\title{
MONITORING LOCATION TRACKER UNTUK KENDARAAN BERBASIS RASPBERY Pi
}

\author{
Ahmad Roihan', Muhammad Sri Bintang Prasetyo ${ }^{2}$, Annas Rifa' ${ }^{3}$ \\ Dosen STMIK Raharja Tangerang ${ }^{1}$, Mahasiswa STMIK RAHARJA Tangerang ${ }^{2,3}$ \\ email :ahmad.roihan@raharja.info ${ }^{1}$, bintang.prasetyo@raharja.info ${ }^{2}$, annas.rifai@raharja.info ${ }^{3}$
}

\begin{abstract}
Abstrak
Belajar dari perkembangan teknologi baru menggunakan Internet sebagai media monitoring, maka dapat dipastikan bahwa gps dapat diaplikasikan dalam berbagai bidang. Sistem-sistem gps menawarkan peningkatan efisien dalam memonitoring kendaran dan mendapatkan data yang akurat dan real time. Bahwa dengan perkembangan teknologi baru itu bisa di kerjakan yang tadinya pekerjaan-pekerjaan manual menggunakan computer yaitu Raspberry Pi. metode pengumpulan data dilakukan dengan metode observasi, metode wawancara dan studi pustaka, metode perancangan alat dilakukan dengan menggunakan aplikasi Fritzing sebagai tools untuk merancang sistem yang akan di buat serta rancangan prototipe yang akan dibangun. Namun sejauh ini sebagian masih bersifat lokal (Intranet), seperti Infrared, Bluetooth dan Wireless LAN. Dengan adanya teknologi terbaru merubah paradigma lokal (Intranet) menjadi IoT / Internet Protocol Based. Dalam perancangan alat ini dibutuhkan Raspberry $P i$ sebagai media Gps serta sebagai media monitoring kendaraan menggunakan GPS, dilengkapi dengan module GPS sebagai media monitoring dengan mudah. Dibuatnya alat ini semoga memberikan kemudahan bagi pemilik kendaraan untuk memonitoring kendaraan dari jarak jauh dan memberikan laporan secara realtime.
\end{abstract}

Kata Kunci: Gps, Raspbery Pi, Internet of Things

\begin{abstract}
Learning from the development of new technologies using the Internet as a monitoring medium, it can be ascertained that gps can be applied in various fields. These gps systems offer efficient improvements in vehicle monitoring and obtaining accurate and real time data. That with the development of new technologies that can be done that was the work-manual work using a computer that is Raspberry Pi. Data collection method is done by observation method, interview method and literature study, tool design method is done by using Fritzing application as a tool to design the system to be made and design of prototype to be built. But so far some are still local (Intranet), such as Infrared, Bluetooth and Wireless LAN. With the latest technology changing the local paradigm (Intranet) into IoT / Internet Protocol Based. In designing this tool required Raspberry Pi as Gps media as well as vehicle monitoring media using GPS, equipped with GPS module as a monitoring medium with ease. The creation of this tool may make it easy for vehicle owners to monitor vehicles remotely and provide reports in realtime.
\end{abstract}

Keywords: Gps, Raspbery Pi, Internet of Things

\section{PENDAHULUAN}

\subsection{Latar belakang}

Dalam perkembangan teknologi di bidang elektronika dan komunikasi sekarang ini penggunaan alat bantu di rasakan sangat penting, karena, dapat membantu segala aktifitas yang dilakukan oleh manusia, industri dan bahkan di pemerintahan khususnya dalam hal memonitoring jarak jauh (remote), tidak lepas dari itu semua penggunaan sistem yang umumnya berbasis komputer dan sistem terkontrol yang menggunakan mikrokontroler sudah sangat maju pada zaman ini, 
diantaranya yaitu dengan digunakannya sistem monitring location tracker untuk memantu kendaraan khsusunya roda empat agar dapat selalu diketahui lokasinya.

Setiap pemilik kendaraan pada khususnya membutuhkan suatu alat yang dapat melakukan pemantauan posisi kendaraan mobil dari jarah jauh. Khususnya untuk perusahaan yang bergerak dalam bidang rental mobil. Oleh karena itu dirancanglah alat Monitoring Location Tracker ini memantau kendaraan dari jarak jauh dan memberikan rasa aman pada perusahaan yang memiliki mobil operasional dan dapat memantau mobil dinas yang berada dilapangan. Sistem yang berbasis Raspberry $P i$ ini dapat dihubungkan kesetiap kendaraan yang bergerak, membuat pilihan yang mudah untuk melacak kendaraan secara real time di Open Map Street keberadaan dari kendaraan tersebut yang terlihat dalam peta dengan menggunakan Open Map Street.

\subsection{Rumusan Masalah}

Dalam rumusan maslah ini memuat uraian secara rinci dari permasalahan yang di identifikasikan pada latar belakang. Adapun rumusan masalah dalam penyusunan penelitian ini adalah sebagai berikut:

1. Bagaimana membuat sistem monitoring location tracker mobil berbasis raspberry?

2. Bagaimana menghubungkan sistem monitorong dengan web ?

3. Bagaimana cara kerja system monitoring location tracker pada kendaraan berbasis raspberry pi ?

4. Apa saja hardware dan software yang digunakan untuk membuat system monitoring loacation tracker mobil dinas berbasis raspberry pi?

\subsection{Ruang Lingkup Penelitian}

Berdasarkan rumusan masalah yang sudah dijelaskan, maka penelitian diarahkan pada perancangan dan pembuatan alat yang dapat diakses melalui smartphone dan web untuk mengakses data secara online menggunakan Raspberry Pi. Maka dari itu peneliti dapat fokus dalam satu bagian. Sehingga data diperoleh akurat, spesifik, dan memudahkan peneliti untuk menganalisa data yang diperoleh, serta komponen pendukung yang meliputi penggunaan mikrokontroller Raspberry pi., modul GPS berfungsi sebagai pendeteksi objek, database ubidot yang diakses menggunakan Browser

\subsection{Tujuan Penelitian}

Berdasarkan permasalah yang diteliti, maka tujuan yang ingin di capai pada pembuatan monitoring location tracker pada kendaraan berbasis raspberry pi adalah sebagai berikut:

1. Menciptakan invovasi terbaru yang sebelumnya tidak ada atau pengembanggan inovasi sebelumnya.

2. Merubah sistem yang sudah ada menjadi lebih modern.

3. Memanfaatkan teknologi yang sudah ada pada saat ini

\subsection{Manfaat Penelitian}

Berdasarkan analisis permasalahan yang telah diteliti,maka dapat dijelaskan manfaat dari penelitian, diantaranya yaitu:

1. Dapat mengurangi kelalaian dalam bekerja.

2. Dapat mempermudah untuk memonotoring mobil patroli pada saat di lapangan.

3. Dapat diakses dimana saja.

\subsection{Metode Penelitian}

Metode Pengumpulan Data

1. Observasi (Pengamatan) 
Merupakan metode pengumpulan data dengan melalui pengamatan secara langsung atau peninjauan secara cermat dan langsung dilapangan atau lokasi penelitian. Penelitian dilakukan dalam jangka waktu 5 bulan di sekitar wilayah tangerang yang menjadi lokasi penelitian guna memperoleh data dari keterangan yang berhubungan dengan jenis penelitian.

2. Wawancara

Merupakan metode pengumpulan data dengan cara melakukan tanya jawab dengan beberapa perusahaan yang memiliki kendaraan dinas serta beberapa pemilik perusahaan yang bergerak dalam bidang jasa penyewaan mobil. Hasilnya diharapkan dengan teknologi ini membuat kemajuan teknologi yang dapat mempermudah mengontrol kendaraan di lapangan.

3. Studi Pustaka

Metode Studi Pustaka, yaitu metode yang digunakan untuk mendapatkan informasidari beberapa sumber-sumber literature seperti buku, jurnal, makalah, internet, dan lain sebagainya yang berkaitan dengan penelitian sebagai bahan referensi dalam penyusunan laporan skripsi ini.

Metode Perancangan

Dalam metode peracangan ini kita dapat mengetahui bagaimana sistem itu dibuat atau dirancang dan alat apa saja yang dibutuhkan. Melalui tahapan pembuatan flowchart dari sistem yang akan dibuat dan pembuat desain aplikasi pengontrolan berupa perancangan perangkat lunak (Software) dan perangkat keras (Hardware).

\section{Metode Prototipe}

Metode prototipe yang digunakan dalam penelitian skripsi ini adalah metode rapid throwaway prototyping adalah cara yang berguna untuk mengeksplorasi ide-ide, dan mendapatkan umpan balik dari klien dan atau pengguna terakhir. Dengan prototype yang terbuka, model sebuah sistem (atau bagiannya) dikembangkan secara cepat dan disempurnakan dalam diskusi yang berkali-kali dengan klien. Karena tujuan dari protoipe ini adalah mengembangkan model menjadi sistem final.

\section{LANDASAN TEORI}

\subsection{Konsep Dasar Sistem Komputer}

Sistem Komputer dapat diartikan sebagai elemen-elemen yang terkait untuk menjalankan suatu aktivitas dengan menggunakan komputer. Adapun definisi mengenai sistem diantaranya adalah:bMenurut Wikipedia, "Sistem komputer adalah suatu jaringan elektronik yang terdiri dari perangkat lunak dan perangkat keras yang melakukan tugas tertentu (menerima input, memprosesinput, menyimpan perintah-perintah, dan menyediakan output dalam bentuk informasi)".Menurut Maarof, Mohd. Aizaini (2004, 5), "Komputer adalah mesin elektronik yang boleh menerima data (input), memproses, menghasilkan keputusan (output) dari proses yang dilaksanakan dan menyimpan keputusan yang dihasilkan untuk kegunaan akan datang".Menurut Webopedia, sistem komputer adalah mesin elektronik yang mencangkup komputer yang bersamaan dengan perangkat lunak dan perangkat periferal yang di perlukan untuk membuat fungsi komputer.

Berdasarkan beberapa pendapat yang dikemukakan diatas dapat ditarik kesimpulan sistem komputer adalah Kumpulan perangkat elektronik yang terdiri dari perangkat lunak dan perangkat keras yang boleh menerima data (input), memproses (process), dan menghasilkan keputusan (output) dari proses yang di laksanakan untuk membuat fungsi komputer. 


\subsection{Karakteristik Sistem Komputer}

Menurut Mohd. Aizaini Maarof $(2015,5)$, "Sistem komputer memiliki karakteristik yaitu terdiri dari perangkat input, unit sistem, perangkat penyimpanan dan perangkat output. Adapun dari karakteristik yang dimaksud adalah sebagai berikut :

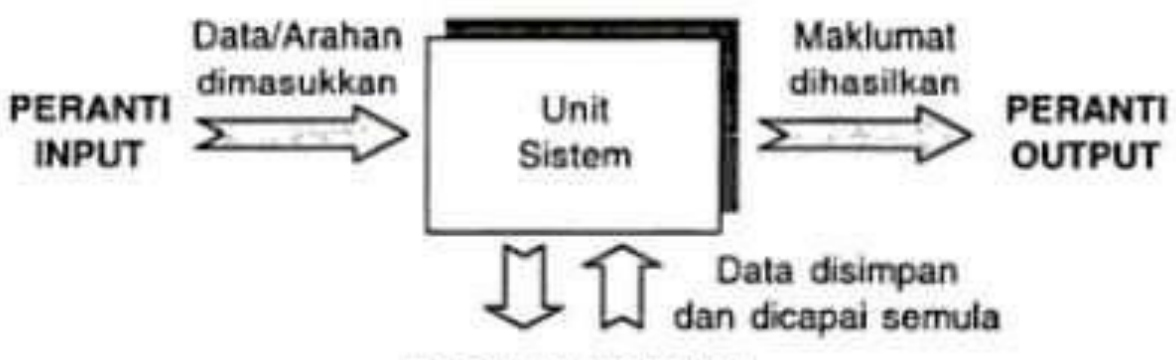

PERANTI STORAN

Gambar 1. Karteristik Sistem Komputer

\subsection{Arsitektur Komputer CISC\&RISC}

Arsitektur Komputer adalah adalah konsep perencanaan dan struktur pengoperasian dasar dari suatu sistem komputer. Selain itu juga dapat didefinisikan dan dikategorikan sebagai ilmu dan sekaligus seni mengenai cara interkoneksi komponen-komponen perangkat keras untuk dapat menciptakan sebuah komputer yang memenuhi kebutuhan fungsional, kinerja, dan target biayanya."Seperti Gambar 2.5 di bawah ini :

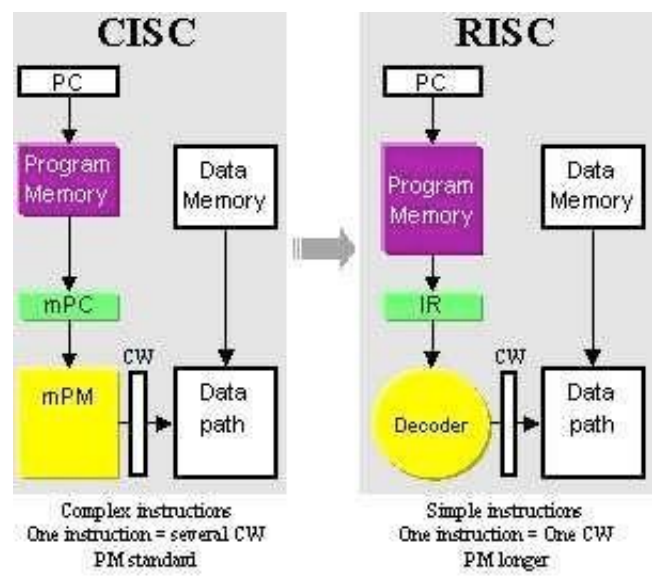

Gambar 2.Arsitektur CISC dan RISC

\subsection{Arsitektur Cisc}

CISC singkatan dari Complex Instruction Set Computer adalah sebuah arsitektur dari set instruksi komputer dimana setiap instruksi akan menjalankan beberapa operasi tingkat rendah, seperti pengambilan darimemori,operasi aritmetika,danpenyimpananke dalam memory,semuanya sekaligus hanya di dalam sebuah instruksi.

Tujuan utama dari arsitektur CISC adalah melaksanakan suatu perintah cukup dengan beberapa baris bahasa mesin sedikit mungkin. Hal ini bisa tercapai dengan cara membuat perangkat keras prosesor mampu memahami dan menjalankan beberapa rangkaian operasi. Contoh-contoh prosesor CISC adalah Intel Pentium 4, Celeron, Dual-core, Core duo, dan Intel Core. 


\section{Arsitektur Arm}

Arsitektur ARM merupakan arsitektur prosesor 32-bit RISC yang dikembangkan oleh ARM Limited. Dikenal sebagai Advanced RISC Machine dimana sebelumnya dikenal sebagai Acorn RISC Machine. Pada awalnya merupakan prosesor desktop yang sekarang didominasi oleh keluarga x86. Namun desain yang sederhana membuat prosesor ARM cocok untuk aplikasi berdaya rendah. Hal ini membuat prosesor ARM mendominasi pasar mobile electronic dan embedded system dimana membutuhkan daya dan harga yang rendah. Seperti Gambar 2.6 dibawah ini :

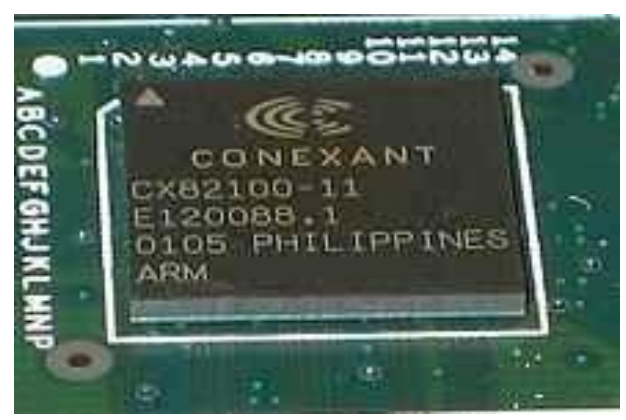

Gambar 3. Sebuah Prosesor ARM dari Conexent pada Router.

\subsection{Arsitektur Risc}

RISC (Reduced Instruction Set Computing), yang jika diterjemahkan berarti "Komputasi Kumpulan Instruksi yang Disederhanakan" merupakan sebuah arsitektur komputer atau arsitektur komputasi modern dengan instruksi-instruksi dan jenis eksekusi yang paling sederhana. Arsitektur ini digunakan pada computer dengan kinerja tinggi, seperti komputer vektor. Selain digunakan dalam komputer vektor, desain ini juga diimplementasikan pada prosesor komputer lain, seperti pada beberapa mikroprosesor Intel 960, Alpha AXPdari DEC, R4x00 dari MIPS Corporation, PowerPC dan Arsitektur POWER dari International Business machine.Selain itu, RISC juga umum dipakai pada Advanced RISC Machine (ARM) dan Strong ARM(termasuk diantaranya adalah Intel XScale),SPARC dan Ultra SPARC dari Sun Microsystems, serta PA- RISC dari Hewlett-Packard.

\subsection{Cloud Computing}

Cloud Computing adalah gabungan pemanfaatan teknologi komputer dan pengembangan berbasis InternetMenurut sebuah makalah tahun 2008 yang dipublikasi IEEE Internet Computing "Cloud Computing adalah suatu paradigma di mana informasi secara permanen tersimpan di server di internet dan tersimpan secara sementara di komputer pengguna (client) termasuk di dalamnya adalah desktop, komputer tablet, notebook, komputer tembok, handheld, sensor-sensor, monitor dan lain- lain."Menurut I putu Eka Agus Eka Pratama dan Sinung Suakanto (2015:213)' "mendefinisikanCloud Computingsebagai sebuah model yang memungkinkan adanya penggunaan sumber daya (resource) secara bersama-sama dan mudah. Menyediakan jaringan akses di mana mana, dapat dikonfigurasi, dan layanan digunakan sesuai keperluan (on demand)".

\subsection{Mikrokontroler}

Menurut Dipranonoto (2010:3), "Mikrokontroler adalah sebagai single chip computer yang memiliki kemampuan untuk diprogram dan digunakan untuk tugas-tugas yang berorientasikan control dari system".

Menurut Syahwil (2013:53), "Mikrokontroler adalah sebuah sistem komputer fungsional dalam sebuah chip. Didalamnya terkandung sebuah inti prosesor, memori, dan perlengkapan inputoutput". 
Menurut pendapat Saefullah, jurnal CCIT Vol.2 No.3 (2013:1), "Mikrokontroler adalah suatu alat elektronika digital yang mempunyai masukan dan keluaran juga kendali dari program yang dapat ditulis dan dihapus secara khusus, cara kerjanya yaitu membaca dan menulis data".

Dari definisi tersebut, maka disimpulkan bahwa mikrokontroler adalah sebuah alat elektronika digital berbentuk single chip komputer, yang didalamnya terdapat sebuah inti prosesor, memori, dan perlengkapan input- output.

\subsection{Pemrograman Phyton}

Pada awalnya, motivasi pembuatan bahasa pemrograman ini adalah untuk bahasa skrip tingkat tinggi pada sistem operasi terdistribusi Amoeba. Bahasa pemrograman ini menjadi umum digunakan untuk kalangan engineer seluruh duniadalam pembuatanperangkat lunaknya,bahkanbeberpa perusahaan menggunakan python sebagai pembuat perangkat lunak komersial. Python merupakan bahasa pemrograman yang freeware atau perangkat bebas dalam arti sebenarnya, tidak ada batasan dalam penyalinannya atau mendistribusikannya. Lengkap dengan source codenya, debugger dan profiler, antarmuka yang terkandung di dalamnya untuk pelayanan antarmuka, fungsi sistem, GUI (antarmuka pengguna grafis), dan basis datanya.

\section{Sejarah Pyhton}

Python dikembangkan oleh Guido van Rossum pada tahun 1990 di CWI, AmsterdamsebagaikelanjutandaribahasapemrogramanABC.Versiterakhir yang dikeluarkan CWI adalah 1.2. Tahun 1995, Guido pindah ke CNRI sambil terus melanjutkan pengembangan Python.Versi terakhir yang dikeluarkan adalah 1.6. Tahun 2000, Guido dan para pengembang inti Python pindah ke BeOpen.com yang merupakan sebuah perusahaan komersial dan membentuk BeOpen Python Labs. Python 2.0 dikeluarkan oleh BeOpen.Setelah mengeluarkan Python2.0,Guido dan beberapa anggota tim Python Labs pindah ke Digital Creations. Saat ini pengembangan Python terus dilakukan oleh sekumpulan pemrogram yang dikoordinir Guido dan Python Software Foundation. Python Software Foundation adalah sebuah organisasi non-profit yang dibentuk sebagai pemegang hak cipta intelektual Python sejak versi 2.1 dan dengan demikian mencegah Python dimiliki oleh perusahaan komersial. Saat ini distribusi Python sudah mencapai versi 2.6.1 dan versi 3.0. Nama Python dipilih oleh Guido sebagai nama bahasa ciptaannya karena kecintaan guido pada acara televisi Monty Python s Flying Circus. Oleh karena itu seringkali ungkapan-ungkapan khas dari acara tersebut seringkali muncul dalam korespondensi antar pengguna Python. Aplikasi bahasa phyton Perangkat bantu shell. Tugas-tugas sistem administrator, program baris perintah. Kerja bahasa ekstensi dan antarmuka untuk pustaka $\mathrm{C} / \mathrm{C}++$.

\subsection{GPS MODULE NEO 6MV2 U-BLOX NEO-6M}

Menururt Tokoduino (2015:7) GPS NEO 6MV2 adalah Modul GPS yang sangat mudah digunakan dan dikoneksikan ke minsys (RASPBERRY PI, dll) dengan koneksi serial TTL 3v3. Tduino. Dengan adanya GPS module ini, minsys anda akan memiliki kemampuan untuk mengetahui posisi (koordinat) dengan bantuan satelit GPS. Seperti gambar 2.8 dibawah ini : 


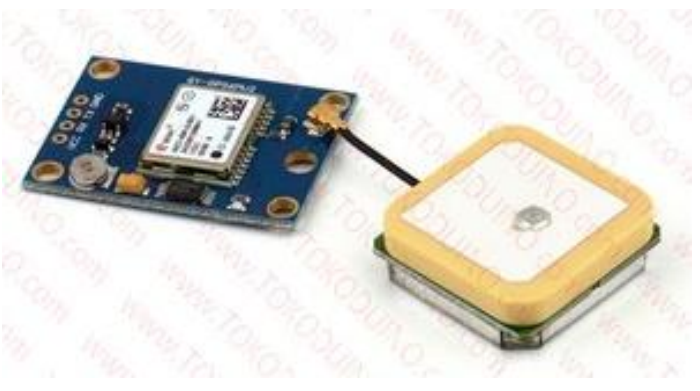

Gambar 4. GPS NEO 6MV2

\subsection{Konsep Dasar Raspberry Pi}

Menurut Monk (2013:1), "The Raspberry Pi is a computer that runs the Linux operating sustem. It has USB scokets you can plug a keyboard and mouse into and HDMI (High-Definition Interface) video output you can connect a TV or monitor into". Raspberry $\mathrm{Pi}$ adalah kompute yang berjalan dengan sistem operasi Linux. Memiliki soket USD yang bisa dipasang untuk keyboard dan mouse, dan keluaran video HDMI (High-Definition Multimedia Interface) dapat dihubungkan ke TV atau monitor.Menurut Richardson dan Wallace (2013Raspberry Pi adalah sebuah komputer sebesar kartu kredit yang terhubung ke televisis dan sebuah keyboard. Komputer kecil ini bisa digunakan untuk proyek- proyek elektronik, dan hal lainnya yang bisa dilakukan oleh desktop komputer seperti sebagaian mesin pengolah kata, games, dan perangkat ini juga memapu memainkan video beresolusi tinggi.Raspberry Pi merupakan sebuah Single Board Computer (SBC) atau computer mini,yangdikembangkanolehraspberryPiFoundationyangberbasis diInggris. Ide awal dari pembuatan Raspberry Pi adalah menyediakan computer yang murah untuk anak-anak sebagai media mereka untuk mempelajari bahasa pemograman komputer. Raspberry Pi diluncurkan pertama kali pada 29 Febuari 2012. Dalam Raspberry Pi sudah dilengkapi dengan prosesor ARM1176JZF-S700 MHz, RAM sebesar 256 MB dan juga sebuah GPU VideoCore IV. Dan untuk penyimpanan data, Raspberry Pi tidak menggunakan Hard Disk namun Raspberry Pi dapat menggunakan SD Card untuk menyimpan data, baik itu data sistem operasinya ataupun untuk media penyimpanan data jangka panjang. Raspberry Pi memiliki dua model, model A dan model B. Perbedaan model A dan B terletak pada memori yang digunakan. Model A menggunakan memori $256 \mathrm{MB}$ dan model B $512 \mathrm{MB}$. Selain itu model B juga sudah dilengkapi denganethernet port (kartu jaringan) yang tidak terdapat di model A.Berikut ini gambar raspberry pi beserta komponen yang ada di dalamnya,seperti gambar 2.10 dibawah ini :

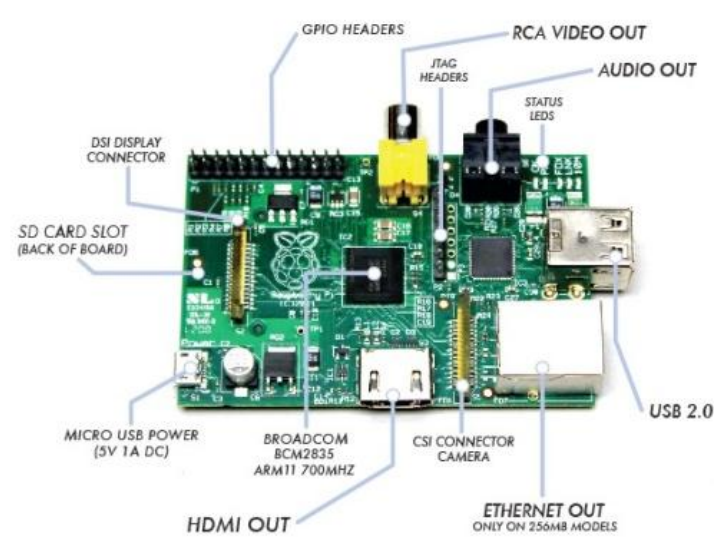

Gambar 5.Raspberry pi dan komponennya 


\section{HASIL DAN PEMBAHASAN}

\subsection{Perancangan Prototipe}

Prototipe sistem akses menggunakan Moduel GPS dan Web berbasis arduino, dalam perancangan disusun menyerupai alat sistem akses pada umumnya. Alat ini dilengkapi dengan komponen seperti: Module GPS, Raspberry Pi, Web dan Personal PC untuk mendukung kinerja alat tersebut. Bahan dalam perancangan prototipe terbuat dari plastik ringan yang digunakan sebagai box komponen.

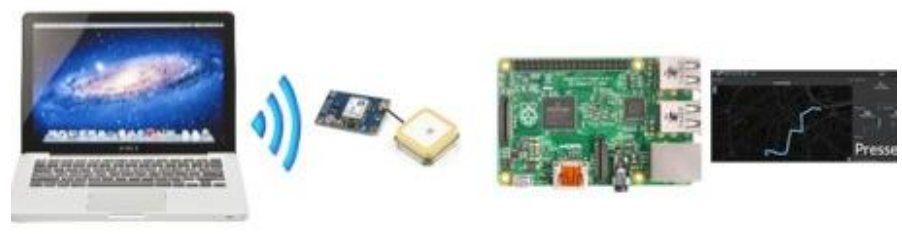

Gambar 6. Perancangan Prototipe

\subsection{Konfigurasi Raspberry Pi}

Raspberry Pi menggunakan sistem operasi Linux bernama Raspbian, sistem operasi terpasang pada SD-card yang sudah di install sistem operasi tersebut sebelumnya. Setelah booting untuk pertama kali kita diminta untuk memasukkan ID: pi dan Password: raspberry yang merupakan ID dan password default dari sistem tersebut seperti gambar 7 sebagai berikut :

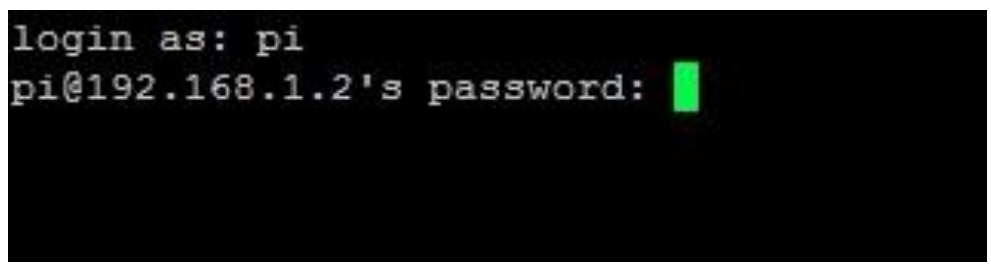

Gambar 7. Login Raspbian

Setelah berhasil Login maka sistemo perasi raspbian sudah siap digunakan dengan tampilan command line seperti gambar 8 sebagai berikut :

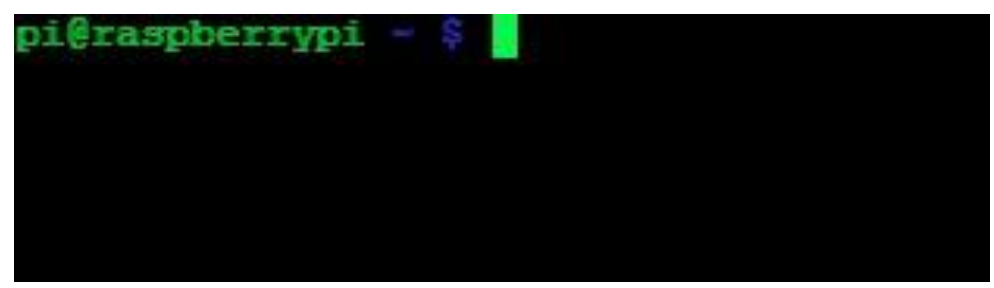

Gambar 8. Melakukan update sistem pada raspberry

Untuk memudahkan pembuatan aplikasi web interface,raspberrypiB+ini akan dihubungkan ke router internet dan menggunakan protocol jaringan SSH untuk me-remote sistem operasi ini dari client yang lain. Setelah Raspberry Pi terhubung dengan jaringan lokal, maka komputer mini ini akan mempunyai alamat IP lokal. Lalu IP lokal tersebut bisa diketahui dengan perintah "ifconfig" seperti gambar 9 sebagai berikut : 


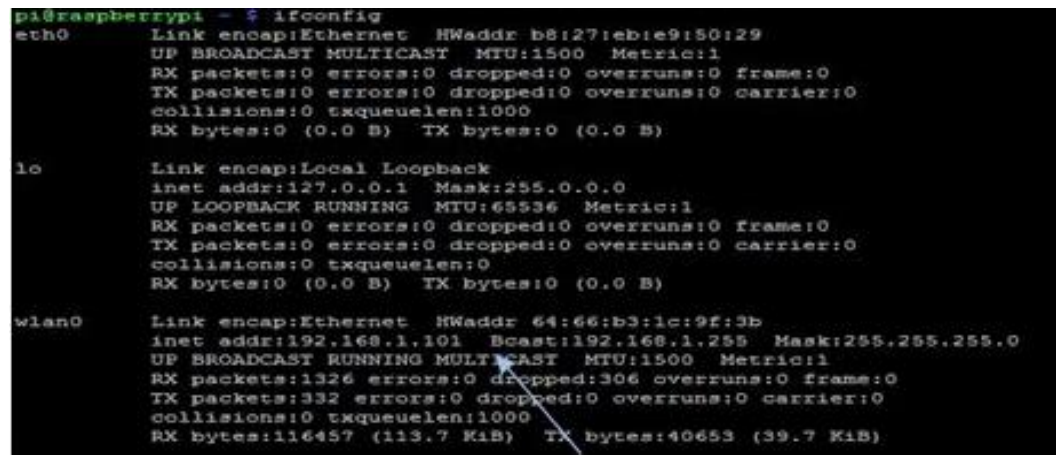

Gambar 9. IP lokal Raspberry Pi

Setelah IP lokal diketahui, Client menjalankan aplikasi putty dan memasukkan alamat IP Raspberry Pi pada kolom HostName.Lalu memilih tipe koneksi SSH dan mengklik tombol open.

\subsection{Konfigurasi Putty}

Memasukan alamat IP Raspberry Pi pada kolom Host Name.Lalu memilih tipe koneksi SSH dan meng-klik tombol open seperti gambar 3.15 sebagai berikut :

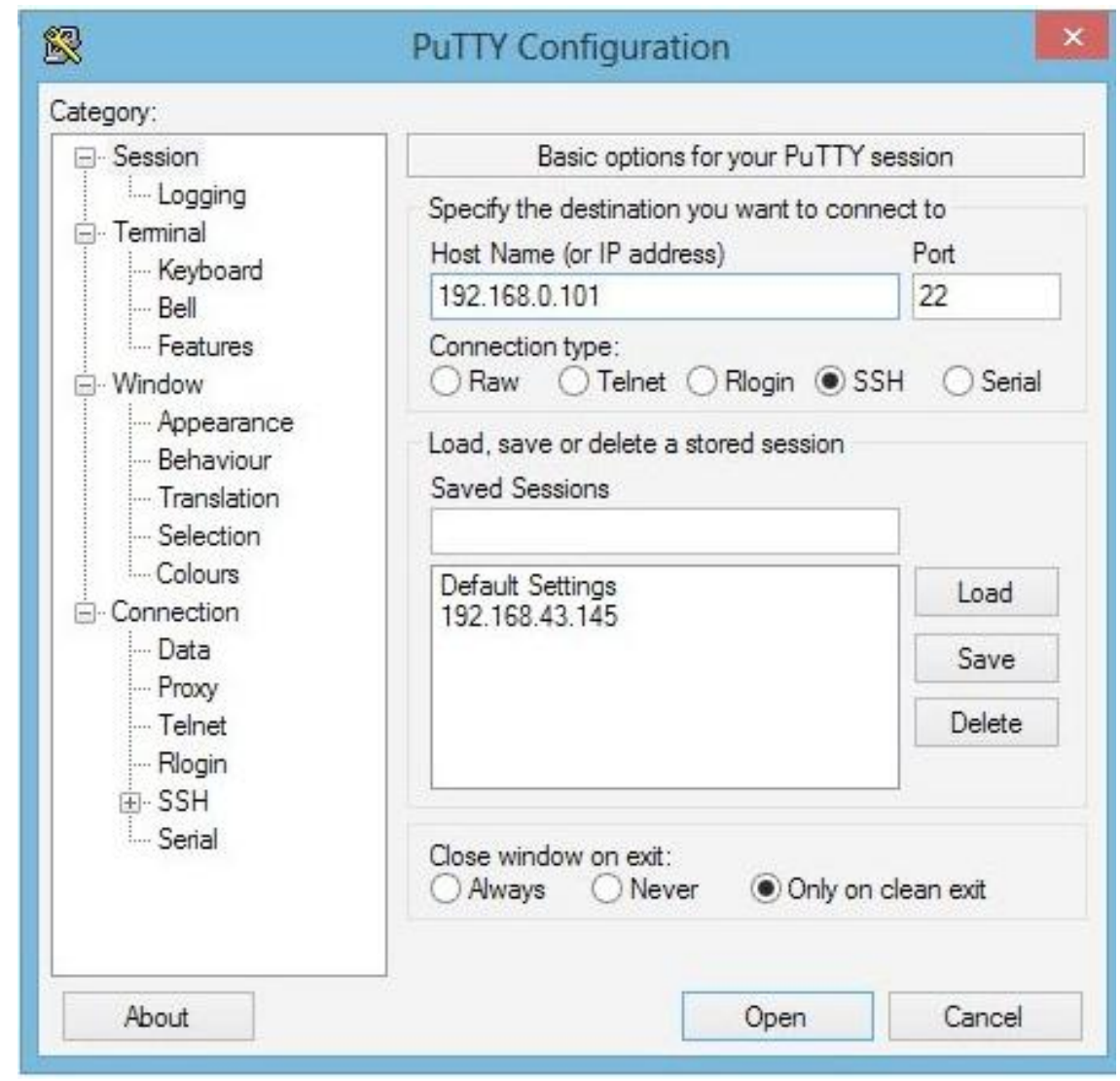

Gambar 10. Konfigurasi Putt

Jika sudah terhubung dan berhasil login pada raspbian melalui client maka aplikasi sudah siap untuk dibuat. 


\subsection{Perancangan software pendukung}

Perancangan perangkat lunak pendukung sangat penting karena diperlukan untuk komunikasi platform dengan perangkat. Adapun langkah-langkah untuk memulai melakukan pemasangan perangkat lunak pendukung dapat dilihat seperti gambar 3.16 ebagaiberikut:

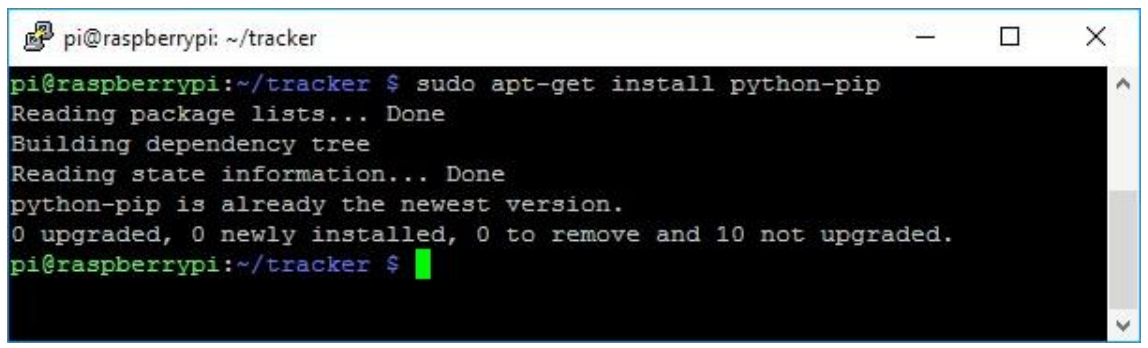

Gambar 11. Library

\subsection{Cara Kerja Alat}

Cara kerja dari sistem Module GPS dan Web sebagai media akses berbasis arduino ini dapat dibagi atas 3 (tiga) bagian. Bagian pertama adalah sistem input, dimana sistem ini merupakan langkah awal dari kerja alat, kemudian sistem prosesyangberkerjamemprosessinyalyangtelahditerimadarisisteminput untuk di keluarkan pada bagian ketiga yaitu sistem output.

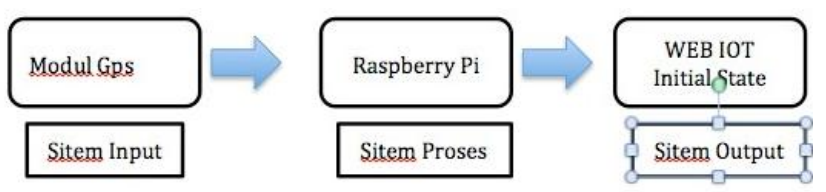

Gambar 12. Cara Kerja Alat

\subsection{Blok Diagram}

Berikut blok diagram berserta alur kerjanya untuk sistem akses pada gambar 13 dibawah ini :

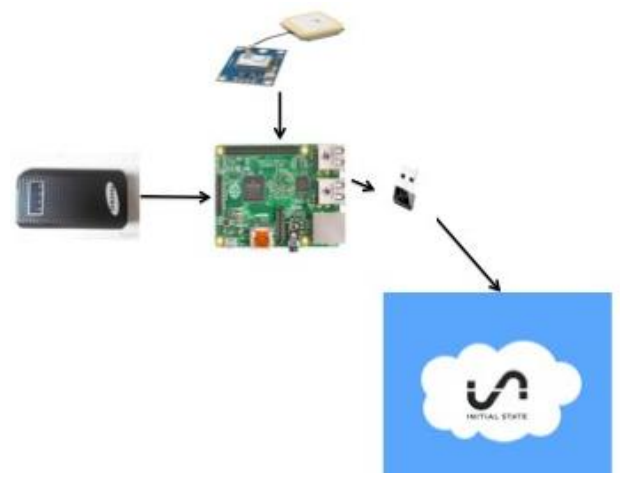

Gambar 13. Blok Diagram

\subsection{Pengujian Rangkaian Gps}

Pengujian yang akan dilakukan pada rangkaian Gps adalah hanya untuk mengetahui dan memastikan bahwa modul Gps dapat digunakan dengan baik, dan ataupun pengujian rangkaian Gps dapat dilihat pada gambar 4.2 berikut ini : 


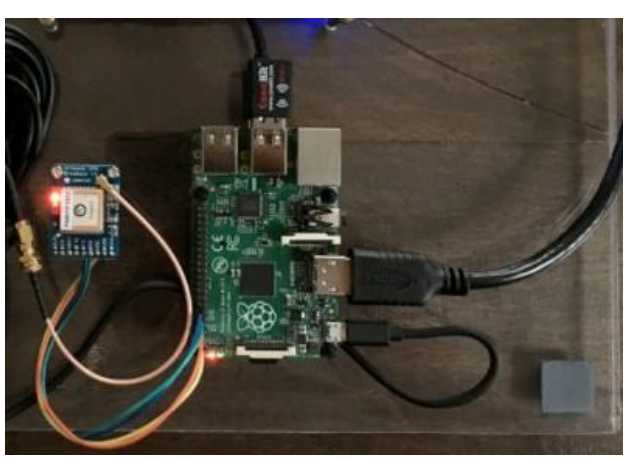

Gambar 14. Pengujian GPS Module

\section{Pengujian Kecepatan lokasi pada beberapa jarak ketinggian}

Sebelum alat siap digunakan terlebih dahulu melakukan pengujian terhadap kecepatan update lokasi pada beberapa jarak ketinggian. Di bawah ini merupakan hasil uji coba alat pada beberapa jarak ketinggian.

Tabel 1 Pengujian Kecepatan lokasi pada beberapa jarak ketinggian

\begin{tabular}{|c|c|c|c|}
\hline No & Ketinggian & Waktu & Status \\
\hline 1. & $10 \mathrm{~m}$ & $24 \mathrm{Menit}$ & Valid \\
\hline 2. & $100 \mathrm{~m}$ & $30 \mathrm{Menit}$ & Valid \\
\hline 3. & $1000 \mathrm{~m}$ & $47 \mathrm{Menit}$ & Valid \\
\hline
\end{tabular}

\section{Pengujian Kendali Melalui Perangkat}

Aplikasi dibuat untuk memonitoring kendaraan patroli adalah aplikas berbasis web. Aplikasi ini dibuat agar nantinya dapat di jalankan denganmenggunakanperangkat apapun yang mempunyai webbrowser. Perangkat-perangkat tersebut seperti Laptop/PC, smartphone, dan tablet. Berikut adalah tabel hasil penngujian dengan perangkat-perangkat tersebut.

Tabel 2 Pengujian Kontrol Melalui berbagai perangkat

\begin{tabular}{|c|c|c|}
\hline \multicolumn{2}{|l|}{ Perangkat } & \multirow[t]{2}{*}{ Hasil } \\
\hline $\begin{array}{l}\text { Nama } \\
\text { Perangkat }\end{array}$ & $\begin{array}{l}\text { Web } \\
\text { Browser }\end{array}$ & \\
\hline Mac & Safari & $\begin{array}{l}\text { 1. Membuka web IoT Initial } \\
\text { State } \\
\text { 2. Yisualisai dapat ditampilkan } \\
\text { 3. Monitoring berjalan dengan } \\
\text { baik }\end{array}$ \\
\hline \multirow[t]{2}{*}{$\begin{array}{l}\text { HandPhone } \\
\text { Android }\end{array}$} & $\begin{array}{l}\text { Chrome } \\
\text { Mobile }\end{array}$ & $\begin{array}{l}\text { 1. Membuka web IoT Initial } \\
\text { State } \\
\text { 2. Yisualisai dapat ditampilkan } \\
\text { 3. Monitoring berjalan dengan } \\
\text { baik }\end{array}$ \\
\hline & Apps Mobile & $\begin{array}{l}\text { Menjalankan app Initial } \\
\text { State } \\
\text { 2. Yisualisai dapat ditampilkan } \\
\text { 3. Monitoring berjalan dengan } \\
\text { baik }\end{array}$ \\
\hline
\end{tabular}

\subsection{Hak Akses (Initial State)}

Dalam membuat sebuah aplikasi perangkat lunak (software) ataupun perangkat keras (hardware) harus dan perlu adanya sebuah hak akses baik oleh petugas yang berwenang atau seseorang yang menjabat sebagai pemegang hak akses sangat diperlukan untuk keamanan dari sistem 
perangkat lunak (software) ataupun perangkat keras (hardware) yang dirancang, karena aplikasi perangkat lunak (software) ataupun perangkat keras (hardware) yang tidak memiliki hak akses akan sangat tidak aman. Adapun sistem ini memiliki dua hak akser user danpassword yaitu password user, sehingga hak akses hanya dapat dilakukan oleh user. Adapau tampilan form login dapat dilihat seperti gambar berikut :

S INITIAL STATE

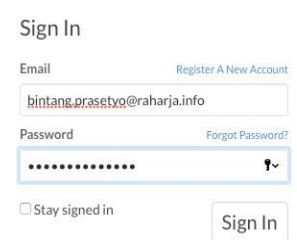

Gambar 15. Tampilan form login untuk hak akses

\section{KESIMPULAN DAN SARAN}

\subsection{Kesimpulan}

Berdasarkan analisa yang telah diuraikan pada bab sebelumnya, maka dapat diambil kesimpulan perihal Penggunaan Gps,smartphone dan WEB sebagai berikut :

Untuk menjawab Rumusan Masalah yang telah dijabarkan sebelumnya, maka penulis mendapatkan hasil:

1. Membuat sistem monitoring location tracker mobil dinasberbasisraspberry yaitu menggunakan platform web IoT.

2. Menghubungkan system monitoring dengan web dari gps diaktifkan masuk ke platform Initial State. Bahwa pekerjaan-pekerjaan yang tadinya manual bisa dikerjakan menggunakan komputer yaitu salah satunya menggunakan Raspberry Pi.

3. Cara mengimplementasikan internet of things, dapat dilakukan dengan membuat rangkaian alat menggunakan Raspberry Pi. Dalam konteks pengontrolan alat,dapat digunakan untuk mengendalikan sensor-sensor dari jarak jauh selama terhubung dengan internet.

4. Hardware dan software yang digunakan untuk membuat system monitoring loacation tracker mobil patroli yaitu (hardware) Raspbery Pi 2, Module Gps, (Software) Bahasa Pyhton, Initial State Api Key Wiring Pi.

Untuk menjawab Tujuan Penelitian yang telah dijabarkan sebelumnya, maka penulis mendapatkan hasil:

1. Menciptakan inovaster baru pekerjaan-pekerjaan yang tadinya manual bisa dikerjakan menggunakan komputer yaitu salah satunya menggunakan Raspberry Pi

2. Hasil yang diharapkan merubah system lama menjadi modern dengan adanya teknologi IoT dimana memonitoring dengen jarak jauh.

\subsection{Saran}

1. Penelitian selanjutnya dapat ditambahkan Google Maps. Karena, dengan google map mengambil gambar dan letak lokasi lebih akurat dan dapat digunakan di smartphone dan device lain. 
2. Penelitian selanjutnya dapat menampilkan foto lokasi supanya pengambilan gambar lokasi secara akurat dan real time

3. Menampilkan bahan bakar yang digunakan pada mobil yang dipantau di lapangan

\section{DAFTAR PUSTAKA}

[1]. Alok Sahelay,Mukesh Bathern,2013.International Journal of Scientific and Enginnering Research. WI-FI Location Tracker System.

[2]. Adelia, dan Jimmy Setiawan. 2011.Implementasi Customer Relationship Management (CRM) pada Sistem Reservasi Hotel berbasisi Website dan Desktop. Bandung:Universitas Kristen Maranatha.Vol.6,No.2,September 2011:113-126.

[3]. Choiriah.2012.Diambildari :Jurnal Tugas Akhir Rancang Bangun Sistem Informasi Penitipan Motor Berbasis WEB Dengan Menggunakan PHP dan Mysql Di Terminal Purwekerto.

[4]. Dermawan,Dr Deni,Nur Fauzi, Kukun.2013.Sistem informasi Manajemen. Bandung: PT Remaja Rosdakarya Offset.

[5]. Darmawan. 2013. Sistem Informasi Manajemen. Bandung: PT. Remaja Rosdakarya Offset.

[6]. Dermawan, Dr. Deni. Nur Fauzi, Kunkun. 2013. Sistem Informasi Manajemen. Bandung: PT Remajan Rosdakarya Offset.

[7]. Fahri,Muhammad Khiabani.2015.Perguruan Tinggi Raharja. dikutipdari :http://widuri.raharja.info/index.php?title=SI1133469703\#BAB_IV (Tanggal akses 12 maret 2016)

[8]. Guritno Suryo, Sudaryono dan Untung Rahardja. 2011. Theory andApplication ofIT Research Metodologi Penelitian Teknologi Informasi.Yogyakarta: CV. Andi Offset

[9]. Gunawan W. dan Gunandi. 2008. Mobile Broadband. Bandung : Informatika

[10]. Iqbal Kurniawan, Mohammad,2016.Universitas Dian Nuwantoro Semarang, rancang bangun perangkat lunak gps based location tracker pada platfrom android untuk pelacakkan lokasi sales pt. meliana perkasa sejahtera.

[11]. I Putu AgusEka Pratama dan Sinung Suakanto. 2015. Wireless SensorNetwork. Bandung : Informatika Bandung.

[12]. Jaza, Khaerul dan Elzet.2014. Perancangan Program Inventory Material Pada PT. Hikari Metalindo Pratama Cikarang Dengan Menggunakan Microsoft VisualBasic 6.0. Jurnal Bina Sarana Informatika Vol.1,No.1,19 November201 4

[13]. Juniarno,Anjar.2015.Perguruan Tinggi Rahardja. SISTEM INFORMASI GEOGRAFIS LOKASI PUSKESMAS KOTA TANGERANG BERBASIS WEB".

[14]. Sutabri, Tata. 2013.Analisis Sistem Informasi . Yogyakarta: CV Andi Offset.Yakub, McLeod 2012 Atmik Raharja

[15]. Maarof, Mohd. Aizaini. 2004. Teknologi Maklumat Siri I : Sistem Komputer dan Perisian. Tersedia di https://books.google.co.id/books?id=VNZHim1aOMwC\&source=gbs_navlink s_s

[16]. Simarmata,Janner.2010.Rekayasa Perangkat Lunak. Yogyakarta: CV Andi Offset.

[17]. Warsito,Ary Budi, Muhammad Yusup, Moh Iqbal.2015. Perancangan SIS+ Menggunakan Metode YII Framework Pada Perguruan Tinggi Raharja.Vol.8 No.2 - Januari 2015.

[18]. Nikolaos Bourbakis, Konstantina S. Nikita and Ming Yang. 2013.

[19]. International Journal of Monitoring and Surveillance Technology Resarch.Vol 1:2, ISSN:21667241, EISSN:2166-725X. IGI PA, USA.

[20]. Pemograman C dan Implementasinya. Informatika Bandung, Desember 2011.

[21]. Patra,Sabyasachi.2015.International Journal of Scientific and Enginnering Research. Locatin Based Tracking. 
[22]. Sulindawati,dan Muhammad Fathoni.2010. Pengantar Analisa Perancangan Sistem. Medan: STMIK Triguna Dharma. Vol. 9, No. 2, Agustus 2010.

[23]. Saefullah, jurnal CCITVol.2No.3(2013:1), Mikrokontroler merupakan suatu alat elektronika digital yang mempunyai masukan dan keluaran.

[24]. Swarjana. I Ketut.2012.Metodologi Penelitian Kesehatan.Yogyakarta:AndiOffset.

[25]. TokoPedia.com.GPSNEO6MV2, diakses pada tanggal 12 mei 2016 tersedia di https://www.tokopedia.com/jualapasajas/ublox-neo-6m-gps-module.

[26]. Wikipedia. Arsitektur Komputer CISC\&RISC. Diakses pada tanggal 26mei 2016. Tersediadi https://id.wikipedia.org/wiki/RISC \&https://id.wikipedia.org/wiki/CISC.

[27]. Wikipedia. Komputasi Awan. Diakses pada tanggal 27 mei2015. Tersedia di https://id.wikipedia.org/wiki/Komputasi_awan\#cite_ref-5.

[28]. Wikipedia. Sistem Komputer.Diakses pada tanggal 21 maret 2016. Tersedia di https://id.wikipedia.org/wiki/Sistem_komputer 